\title{
Modelo multicausal de la enfermedad: tuberculosis
}

\author{
Multicausal model of the disease: tuberculosis
}

\author{
Wendy Y. González-Maldonado ${ }^{a}$, Nancy Rodríguez-Trejo $^{b}$, Eloisa E. Vargas-Cano $^{c}$
}

\begin{abstract}
:
The study of the causes of mortality has served to generate hypotheses about the etiology of diseases, describe the patterns of change over time and also to estimate the prevalence of disease among groups of people or geographic areas. Traditionally, these studies have been based on the analysis of a single cause of death, the basic cause, however, mortality from tuberculosis has characteristics to be studied with a multiple-cause approach, since this disease generally does not cause death, but is found linked to many deaths. The determination of health and disease is in the triad of agent, host and environment.
\end{abstract}

Keywords:

Tuberculosis, agent, host, ambient

\section{Resumen:}

El estudio de las causas de mortalidad ha servido para generar hipótesis acerca de la etiología de las enfermedades, describir los patrones de cambio a lo largo del tiempo y también para estimar la prevalencia de enfermedad entre grupos de personas o áreas geográficas. Tradicionalmente, esos estudios se han basado en el análisis de una única causa de defunción, la causa básica sin embargo la mortalidad por tuberculosis reúne características para ser estudiada con un enfoque de causa múltiple, ya que esta enfermedad generalmente no produce la muerte, pero se encuentra vinculada a muchas defunciones. La determinación de la salud y la enfermedad está en la triada agente, huésped y al ambiente.

\section{Palabras Clave:}

Tuberculosis, agente, huésped, ambiente

\section{Síntesis}

El presente documento aborda el modelo multicausal de la enfermedad de la tuberculosis donde se plantea que ningún poblema de salud responde a una causa única si no que extisten varios factores involucrados como agentes, el ambiente y el huesped que favorecen la propagación y/o reproducción de dicha enfermedad.

\footnotetext{
a Universidad Autónoma del Estado de Hidalgo, https://orcid.org/0000-0003-1000-020X, Email: go413637@uaeh.edu.mx

b Universidad Autónoma del Estado de Hidalgo, https://orcid.org/0000-0001-5233-9530, Email: ro413642@uaeh.edu.mx

Autor de correspondencia, Universidad Autónoma del Estado de Hidalgo, https://orcid.org/0000-0001-5424-5124, Email: eloisaevc@gmail.com
} 


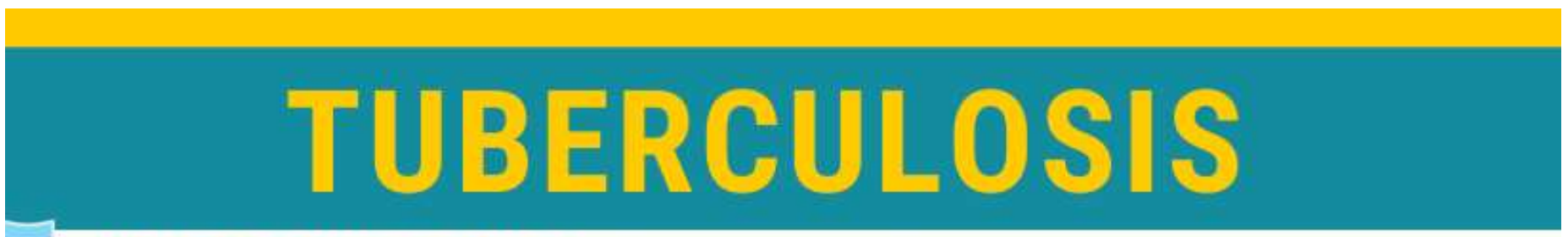

MODELO MULTICAUSAL Plantea que ningún problema de salud responde a una causa única, aún los de origen bacteriano y para que se produzca un determinado problema, es necesaria la participación de diversos factores.

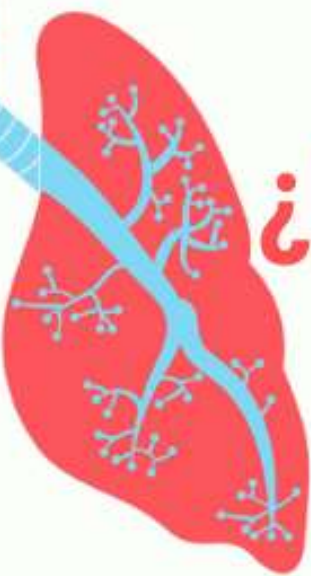

\section{QUÉ ES?}

La Tuberculosis es una enfermedad infecto-contagiosa, causada por un grupo de bacterias del orden de Actinomicetales de la familia Mycobacteriaceae, el complejo M. tuberculosis se compone por el M. Tuberculosis, M. bovis, M. africanum, M. microti, M. canetti.

Es una enfermedad sistémica que afecta mayoritariamente al sistema respiratorio.

\section{TRIADA ECOLÓGICA}

M. tuberculosis, , M. bovis M. africanum, M. microti, M. canett.

\section{Hacinamiento}

Lugares con poca higiene. Condiciones de pobreza. La ausencia y baja cobertura de inmunización con BCG. Explotación infantil.
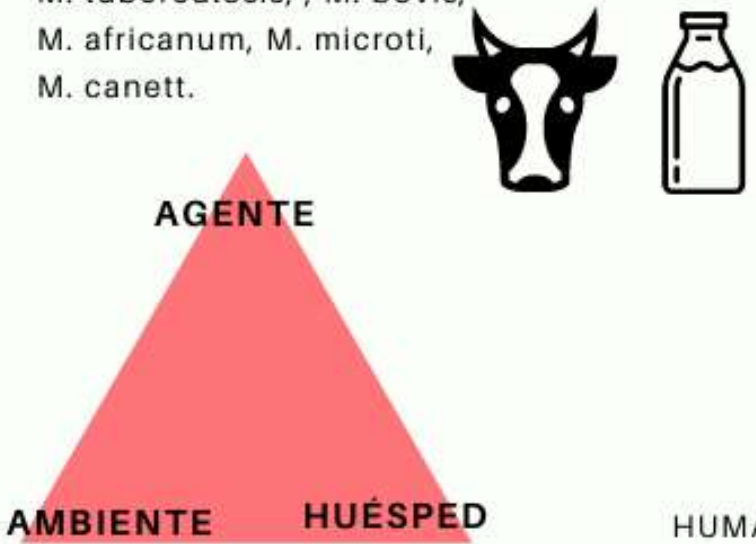

Contacto intradomiciliario frecuente con baciliferos.
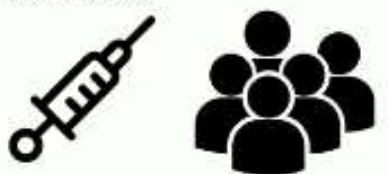

Estado inmunosupresor (VIH) Condiciones médicas (diabetes, silicosis, desnutrición, neoplasias). - La edad pediátrica es la mas ก1 afectada

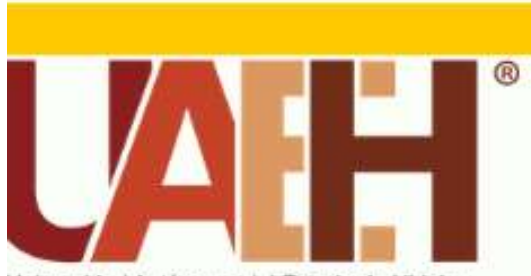




\section{Referencias}

[1] Arango, M. (2015). Historia NaturalDe La Tuberculosis. Fisiopatogenia De La Infección Y La Enfermedad, 10 (4), pp. 155 - 159.

[2] Anónimo (2015). Secretaria de Salud, Tuberculosis. Recuperado de http://www.cenaprece.salud.gob.mx/programas/interior/micobacteriosi s/descargas/pdf/tuberculosis.pdf 